\title{
La libertad de prensa en el pensamiento de Rafael Correa
}

\section{Freedom of the Press in the Rafael Correa' Thought}

\author{
Abner Barrera Rivera \\ Instituto de Estudios Latinoamericanos \\ Universidad Nacional, Costa Rica \\ dan.barrera.rivera@una.cr
}

\begin{abstract}
Resumen
El propósito de este artículo es sistematizar parte del pensamiento de Rafael Correa respecto a la libertad de prensa. Se analizan veinte entrevistas que le fueron realizadas por los medios de comunicación. A partir del tema principal se seleccionan los subtemas; se exponen los argumentos de Correa, y se señalan las reacciones de los periodistas respecto al punto de vista del entrevistado. Se concluye que los grandes medios son actores políticos que han convertido la información en mercancía. Para garantizar la libertad de prensa, se plantea que los medios sean públicos y estén supervisados por la sociedad civil. Se propone la creación de nuevas leyes que aseguren la independencia, pluralidad y democracia de los medios.
\end{abstract}

Palabras claves: libertad de prensa, derechos humanos, actores políticos, Rafael Correa 


\begin{abstract}
The purpose of this article is to summarize Rafael Correa's thoughts towards the freedom of the press. It analizes twenty interviews that were made by different means of communication. Beggining with the main topic some other topics are chosen; Mr. Correa's arguments are presented and the reaction of the journalists and reporters towards his point of view is shown. The article points that the great media has become a political actor that has turned information into a commodity. In order to guarantee the freedom of the press, it posed that mass media companies should be public and supervised civil society. It proposes the creation of new laws to guarantee the independence, plurality, and democracy of the media.
\end{abstract}

Keywords: freedom of the press, human rights, political actors, Rafael Correa

\section{Introducción}

$\mathbf{E}$ 1 presidente Rafael Correa Delgado durante sus diez años de gobierno en Ecuador (2007-2017) llamó la atención de la clase política y la sociedad civil en general por su posición crítica respecto al papel de los grandes medios de comunicación en las sociedades democráticas. Los medios nacionales e internacionales se interesaron por conocer lo que pensaba acerca de la libertad de prensa. A diferencia de otros presidentes, Correa siempre ha expuesto sus ideas y las ha confrontado con las de los propios detentores del poder mediático. En varias ocasiones ha dicho que sus "colegas (presidentes) se quejan en privado de los excesos de la prensa, e incluso algunos piensan que es mejor soportar todo lo que les dicen porque de lo contrario es peor"; pero él siempre ha estado dispuesto a debatir y ha marcado posiciones críticas acerca del papel que asumen quienes -dice él-, creen ser los dueños de la opinión de los pueblos. En entrevista con Desayunos de TVE, dijo:
Si algo he aprendido en este oficio es responderle a la gente, no a los medios de comunicación; ustedes se creen propietarios de la opinión pública, no, ustedes son propietarios de la opinión publicada; la opinión pública es la de nuestros pueblos, y a ellos hay que contestarles. (Sucreranda, mzo. 2012)

En Internet hay más de ochenta entrevistas que le han sido hechas en más de veinticinco países (Argentina, Brasil, Bolivia, Colombia, Costa Rica, Cuba, Chile, Ecuador, El Salvador, Guatemala, Nicaragua, México, Paraguay, Perú, República Dominicana, Uruguay, Venezuela, Alemania, Bélgica, Italia, Estados Unidos, Inglaterra, Francia, Rusia, China, Estado de la Ciudad del Vaticano, Estado de Catar); en varios de esos países fue entrevistado hasta en siete ocasiones y para diferentes medios. Además de haber sido abordado por canales estatales y privados (nacionales), ha sido entrevistado también por medios internacionales como Página 12. Cubavisión, Radio Vaticana, Univisión, 
CNN, Telemundo, AP, The Wall Street Journal, Telesur, RTVE, BBC, Rusia Today, The Guadian, CGTN World Today de China, TV5 Monde de Francia, Sputnik, entre otros.

La posición de Correa sobre el derecho a la libertad de prensa es inédita en América Latina. Si bien otros presidentes han mantenido posiciones semejantes e incluso han aprobado nuevas leyes sobre los medios en sus países, ha sido él quien ha planteado la información como un derecho humano, ha cuestionado la mercantilización de la información y ha defendido el derecho de las personas a tener acceso a una prensa libre, independiente y plural. Para este estudio se escogieron veinte entrevistas que tratan con amplitud el tema.

\section{Los videos y las entrevistas como fuente de conocimiento}

Al igual que los documentos escritos, los videos son una fuente para la investigación de diversos temas relacionados con la sociedad; ahí se registran las ideas en la voz de los propios personajes; y en este caso el valor es mayor porque aún no existe ninguna investigación al respecto. El estudio se propone sistematizar las ideas del ex mandatario ecuatoriano sobre la libertad de prensa; es un pensamiento que se encuentra diseminado en cientos de horas de conversación con los medios. Para eso se precisan los subtemas (que aparecen más adelante como subtítulos) que giran en torno al tema principal; se exponen los argumentos del entrevistado sobre cada subtema; y se señalan las reacciones y posiciones de los entrevistadores sobre el punto de vista del entrevistado.
En el periodismo la entrevista es un medio de obtención de información a través del diálogo, el cual permite explicaciones, aclaraciones, desmentidos, réplicas, etc. Es el género que está en la misma base del quehacer periodístico, porque es el encuentro en estado puro entre el periodista y la fuente primaria que es el entrevistado; cumple varios propósitos: a) presentar al televidente quién es y cómo es tal personaje; b) dar a conocer un tema nuevo o c) lo que piensa el entrevistado respecto a un tema que concita la atención de la gente. Este tipo de periodismo se conoce también como la entrevista informativa, que tiende a preponderar hoy a costas de la propia investigación periodística (Quesada, 2008, p. 7).

Se seleccionaron las entrevistas que fueron en vivo (ver bibliografía); buena parte de ellas pertenecen a la Secretaría Nacional de Comunicación (SECOM), órgano oficial de Ecuador. El gobierno de Correa grababa todas las audiencias previendo que hubiera alguna discrepancia (593Ecuador, ene. 2017). En algunas de ellas, hubo reporteros que se quedaron sin argumentos al defender sus puntos de vista. Hay otros videos en donde algunos periodistas despotrican contra Correa en su ausencia; un caso es el que protagonizó el periodista Mario Saldaña, un día después de que Correa abatió sus argumentos (Peru info, nov. 2013). También hay videos editados, donde tergiversan las ideas de Correa; estos han sido denunciados en su momento por el gobierno ecuatoriano de entonces. 


\section{La gran prensa y los gobiernos progresistas}

Desde principios de este siglo, en América Latina el poder mediático viene utilizando la libertad de prensa para defender intereses ajenos al periodismo. La información es un derecho humano y el deber de los medios es informar libremente con imparcialidad, independencia y pluralidad, para contribuir a la cultura, la educación y el conocimiento. Pero la realidad muestra que los oligopolios de la comunicación han transformado la información en mercancía. En los gobiernos neoliberales de América Latina la gran prensa define la agenda legislativa, asume la voz y representación de la sociedad, toma partido en las contiendas electorales, hace abiertamente campaña política por los candidatos de su preferencia, coloca y destituye presidentes e influye en los poderes del Estado.

Los países en los que la gran prensa ha tenido dificultades han sido aquellos donde ha habido gobiernos progresistas: en Venezuela con Hugo Chávez y Nicolás Maduro, en Brasil con Luiz Inácio Lula da Silva y Dilma Rousseff, en Argentina con Néstor Kirchner y Cristina Fernández, en Bolivia con Evo Morales, en Ecuador con Rafael Correa y en Uruguay con José Mujica. La confrontación ha sido entre el gobierno, la sociedad civil y los movimientos sociales por un lado, y los oligopolios de la comunicación por otro. Después de debates, propuestas, estudios y movilizaciones sociales, se aprobaron nuevas leyes de comunicación en Venezuela, Argentina, Bolivia, Ecuador y Uruguay; pero con la elección de nuevas autoridades, esas leyes tuvieron reveses en algunos de esos países.
De todos los gobernantes progresistas, ha sido Rafael Correa quien más ha analizado, debatido, argumentado y cuestionado el papel que desarrollan los oligopolios de la comunicación en la democracia. Desde que asumió la presidencia, su relación con los medios fue controversial; a pocos meses de haber empezado su primer mandato, inició un juicio contra algunos periodistas porque le expresaron amenazas e injurias. En adelante no fueron pocas las confrontaciones. Desde joven conoció el poder de la prensa: en 1986, cuando era presidente de la Federación de Estudiantes Universitarios Particulares del Ecuador (FEUPE), había acordado con el periódico El Universo para que cubriera "La semana de la Paz" en Guayaquil. Pero no se logró porque los dueños del diario al enterarse de que había firmado un manifiesto de apoyo a una ley que prohibiría la publicidad de cigarrillos y alcohol en los medios, decidieron no cubrir el evento. Desde ese hecho, dice él, nunca más le dejaron ingresar a El Universo.

\section{El set televisivo como escenario de confrontación}

Rafael Correa ha defendido la libertad de prensa como derecho humano no sólo desde una tribuna pública o a través de un discurso -como otros políticos-, sino también con interlocutores directos, polemizando en el propio terreno del poder mediático.

La tribuna y el set televisivo son escenarios muy diferentes; en el primero, el disertador lleva un mensaje que ha elaborado antes y lo expresa a un público que por lo general simpatiza con él, y si hay alguien que no está de acuerdo, no tiene 
posibilidad de discutir con el expositor; ahí, por lo general, el político suele ser vitoreado. En el segundo escenario, el entrevistado no lleva un mensaje preparado, porque asiste a una audiencia donde le preguntarán sobre diversos temas que él no conoce de antemano; aquí, cuando el invitado expresa sus ideas, el entrevistador puede repreguntarle, pedirle más explicaciones e incluso discrepar con él. En varias entrevistas con Correa, los reporteros olvidaron la deontología periodística y pasaron a refutar, cuestionar y defender posiciones políticas.

En el primer escenario, el orador puede ser ovacionado (tiene un público cautivo); en el segundo, el invitado puede ser interrumpido por el periodista. En el espacio público, la tribuna y el micrófono son del político, quien tiene el control, maneja los tiempos y decide cuándo concluir. En una audiencia televisiva, aunque la palabra y el set son compartidos por el entrevistador y el entrevistado, éste no tiene el control; es el conductor quien decide qué temas se tratan (qué temas no), controla los tiempos y decide cuándo terminar. En la tribuna, por lo general, quien organiza el evento es el mismo político o sus partidarios; en el segundo, quien organiza la entrevista es el medio de comunicación o el director del programa (en la prensa privada por lo general se sigue la línea editorial de la empresa).

De modo que es muy diferente abogar con discursos desde una tribuna pública por la libertad de prensa como derecho humano, que lidiar con el "adversario" en su propia casa, analizando y dando razones para defender una posición contraria a la del anfitrión. Puede decirse que Correa abordó en casa ajena uno de los temas más blindados por la censura mediática, como es el de la naturaleza antidemocrática de los grandes medios de comunicación privados. Por primera vez, la audiencia escuchó una crítica seria al sistema global de estos medios y así sus propias contradicciones. Correa trató temas proscritos en esos espacios, logrando que la gente escuche opiniones que son sistemáticamente censuradas; fueron temas sobre los cuales la gran prensa no admite análisis y críticas que apunten a su falta de legitimidad social y a su carácter antidemocrático.

\section{La libertad de prensa: tema central en las entrevistas}

La Ley de Comunicación aprobada por la Asamblea Nacional de Ecuador (14 de junio de 2013) contiene algunas de las ideas de Rafael Correa; sin embargo, en las audiencias televisivas él analiza, argumenta, razona y reflexiona con mayor profundidad; muestra un pensamiento político propio del tema, que no tiene que ver sólo con Ecuador, sino con toda América Latina. Las entrevistas fueron antes, durante y después de dicha ley.

Cuando la prensa entrevista a un presidente, le consulta sobre distintos aspectos de su país, pero en el caso de Correa, en casi la totalidad de las entrevistas, los periodistas centraron su atención en el tema de la libertad de prensa y sobre él tuvieron muchas discrepancias.

A diferencia de otros presidentes, Rafael Correa no proviene de las canteras políticas partidarias, sino de la academia. Se considera una persona humanista y de 
izquierda, identificado con el socialismo del siglo XXI. Sostiene que su pensamiento político, económico y social está inspirado en la Doctrina Social de la Iglesia, la Teología de la Liberación y el Evangelio. Ha estudiado en colegios católicos y toda su vida ha sido creyente; en su juventud fue profesor de religión. Sus estudios de economía los realizó en universidades de Ecuador, Bélgica y los Estados Unidos. Hasta la fecha, cuenta con quince doctorados honoris causa, otorgados por universidades de Chile, Argentina, Paraguay, Perú, Cuba, República Dominicana, Francia, España, Rusia y Turquía. Se trata de una persona instruida, con principios firmes. Varios de quienes le han entrevistado no han ocultado sus desacuerdos. Sin embargo, gracias a esas entrevistas, algunos se convirtieron en periodistas reconocidos internacionalmente (Lo que tu Buscabas, oct. 2016).

Desde hace tres lustros en América Latina, los gobiernos progresistas han estado trabajando por reconocer, garantizar y defender la información como un derecho humano; han promovido que la prensa sea diversa, democrática e independiente. Esto explica por qué algunos periodistas cuando entrevistaban a Correa reaccionaban con vehemencia a sus planteamientos y expresaban opiniones como si el medio de comunicación al que representaban fuera un poder político institucional incuestionable y superior a los poderes del Estado; dejaban entrever que han naturalizado la gran prensa como un poder infalible, contra el que no se permite objeción, ni ley que lo regule; iquien critique a la prensa atenta contra la libertad de expresión! Por eso no aceptaban que Correa cuestionara a los grandes medios al señalar que habían convertido la información en una mercancía.

A continuación se encontrará en siete apartados (subtítulos) las ideas principales del pensamiento de Correa acerca de la libertad de prensa.

\section{La dictadura de los medios de comunicación}

Esta es una de las primeras ideas que sobresalen en las entrevistas. Según Correa, en un régimen democrático, el poder informativo es el mayor de los poderes. Sostiene que en las sociedades latinoamericanas los medios han llegado a dominar los Estados y han tenido control sobre la gente. Históricamente, los gobiernos latinoamericanos han sido prisioneros de los grupos de poder mediático, lo que ha devenido en una dictadura de los medios. Lo que la gente cree, sabe y conoce depende de lo que los dueños de los medios deciden informar (Peru info, mayo 2012). Todos los días, los medios abusan sin escrúpulos de ese poder y se revisten de legitimidad y a eso, erróneamente, le llaman libertad de expresión. Cree que, en general, la prensa en América Latina es de las peores del mundo. En entrevista con la Televisión Nacional de Chile, el periodista le consulta si esa apreciación incluye también a Chile. Correa, invitándole a pensar en los hechos de ese país, dice: “¿Cuál fue el rol de la prensa en la caída de Allende y en la dictadura de Pinochet? ¿Qué publicaban ciertos medios sobre esos acontecimientos? Y, sobre todo eso, nunca hubo ningún sancionado." (SECOM, 14 may. 2014). 
Aunque la prensa reconoce ser el cuarto poder, necesita un contrapoder en la democracia, pero este no existe. Piensa que la sociedad tiene no solo el derecho, sino también el deber de regular los poderes (político, económico o mediático) y esto se logra por medio de leyes. En entrevista con la agencia AP, la periodista le pregunta: "¿Por qué [Correa] acusaba a los medios de ser opositores?". Él explica que en Ecuador los grandes medios siempre tuvieron un rol político, "eran juez y parte, y se habían acostumbrado a mandar; no importaba quién llegara al gobierno, porque ellos eran quienes establecían la agenda política con sus titulares"; ponían y sacaban presidentes; con dos titulares en el mayor diario del país El Universo, derrocaban un gobierno (SECOM, oct. 2015).

En las entrevistas estudiadas son pocos los periodistas que admiten el poder que tienen los medios. Walter Martínez, de Telesur, sostiene que los políticos generalmente le rinden pleitesía a los medios para que les permitan formarse una imagen y tener presencia en la pantalla chica. Correa afirma que ese es el "poder de los poderes", y es el gran desafío de la humanidad del siglo XXI; la gente le tiene temor a la prensa, porque "quién osa cuestionar el poder mediático, peor que Torquemada es condenado a la hoguera, previa tortura". Los dueños de los medios quieren hacer creer que criticarles sus negocios, su mediocridad, su evasión de impuestos, su explotación laboral, es criticar la libertad de expresión; "eso es tan absurdo como decir que criticar a un gobierno es criticar la democracia" (OmarAli69, dic. 2012).

\section{El papel político de los medios de comunicación}

La segunda idea presente en las entrevistas es acerca del papel político que ejercen los medios. Aunque su rol debe ser informar, con objetividad e independencia, no lo hacen, porque se han convertido en actores políticos, que trabajan a favor o en contra de algún candidato y defienden intereses particulares. Señala que la principal resistencia que están encontrando los gobiernos progresistas en América Latina es el sector mediático que quiere controlar el poder político. Son los dueños de los grandes medios quienes llevan a cabo una ofensiva ideológica, porque la oposición -en este caso la oposición ecuatoriana- no tiene fuerza para resistir ante la voluntad democrática de la población: "por ser los dueños de los medios consideran que ellos tienen la legitimidad para llevar a cabo una oposición a veces con argumentos muy poco serios" (SECOM, mzo. 2012).

Pero el caso ecuatoriano no es aislado; esto sucede en varios países latinoamericanos y el problema es mayor, porque esos "nuevos" actores políticos no asumen la responsabilidad política de sus actos. Lo que sucede con un presidente es distinto, porque está expuesto a mecanismos de control y el pueblo lo juzga en las urnas cada cuatro años. Un presidente es responsable civil y penal por sus actos, no así los medios, cuyos periodistas hacen política sin sufrir la consecuencia de sus actos, y eso perjudica la democracia. Correa piensa que deben definirse: $¡ O$ son periodistas o son políticos! Pero no deben escudarse en el periodismo siendo políticos. Suelen manipular u ocultar los aciertos del 
gobierno por tratarse de un gobierno progresista, pero los logros nunca son noticia: “Cuando se trata de 'desaciertos' del gobierno (a veces inventados) los convierten en noticia de primera página; ahí hay manipulación y asimetría total" (SECOM, oct. 2015). Cuestiona que los medios se hayan convertido en actores políticos y no estén dispuestos a aceptar cuestionamientos políticos; por eso dice: "Si quieren ser actores políticos, entonces que no compren una imprenta, sino que pongan un partido político; deben ser un poco más honestos" (OmarAli69, dic. 2012).

Refiriéndose a la inmunidad a la crítica que los medios de comunicación pretenden tener (situación que se repite en América Latina), dice que hay medios que conspiran todos los días una nueva mentira, desinforman y manipulan, pero cuando se les critica, entonces "es poco menos que criticar a Dios; ellos se sienten que están por encima de la ley y que no se les puede cuestionar" y se defienden diciendo que se está atetando contra la libertad de expresión: "me recuerda a la época de la Colonia, donde para seguir bajo el yugo español nos decían que criticar al rey era criticar a Dios." Considera que no es sano para la democracia que los medios dejen de comunicar e informar y se conviertan en un contrapoder del gobierno, ejerciendo así un rol político: "Lo que llama la atención es que cada vez que se les da una respuesta política, reaccionan, diciendo, atentado a la libertad de expresión" (SECOM, jun. 2011). Hay periodistas que se escudan en su profesión, creyendo que eso les hace inmunes ante la ley. Correa muestra el poder que tienen los medios y los periodistas en comparación con los ciudadanos de a pie:
Si un periodista te calumnia y le pones un juicio por daños morales, entonces eso es atentado contra la libertad de expresión; pero si la denuncia fuera contra un bombero o un arquitecto -también por calumnias-, entonces ahí no hay atentado contra la libertad de expresión. (OmarAli69, dic. 2012)

\section{Conflictos de intereses entre lo privado y lo público}

Según Correa, el papel de los medios, en tanto responsables de brindar un derecho humano como es la información, no se logra, porque hay un conflicto de intereses. Piensa que los dueños de los grandes medios de comunicación pudieron poner un casino, un burdel o un colegio privado, pero pusieron un medio de comunicación y eso les da poder, y se acostumbraron a quitar y poner presidentes, legislar, juzgar, absolver, condenar, etc.; "se acostumbraron a un estado de opinión, y en América Latina debemos inaugurar los estados de derecho, por el bien de todos, donde nadie esté por encima de la ley, empezando por los medios de comunicación" (OmarAli69, dic. 2012).

Esta idea la desarrolla ampliamente en una entrevista con Desayunos de la televisión española, donde explica que hay una contradicción de principio, porque la comunicación social es un bien público fundamental para la sociedad, por lo que no debe estar en manos de negocios privados, porque el fin de estos es el lucro: “¿Qué prevalece cuando un medio de comunicación es dueño de la banca y tiene que criticar a la banca?" Los dueños de los medios siempre impondrán el fin de lucro (Sucreranda, mzo. 2012). Para él es 
incompatible que negocios privados con fines de lucro provean un bien público como lo es el derecho a la información. En varias entrevistas ha dicho: "Desde que se inventó la imprenta, la dichosa libertad de prensa no es otra cosa que la voluntad del dueño de la imprenta”.

Para explicar su pensamiento, Correa siempre recurre a las ilustraciones. Al referirse a la información como derecho humano, señala cuatro de ellas: 1) ¡Imagínese la Administración de Justicia en manos de negocios privados con fines de lucro! Sería contradictorio, porque la justicia por ser un bien común (derecho humano), no puede ser facilitada ni garantizada por una empresa que se dedica a lucrar. De la misma forma, el derecho a la información que es un bien común, no puede estar en manos privadas (Consuladosf, abr. 2012). 2). Para explicar la diferencia entre un bien público y uno privado, usa el ejemplo de la corbata (bien privado): si una persona compra una corbata horrorosa, quien queda en ridículo es esa persona que compra la corbata; pero la información no es como una corbata, es decir, no es un bien privado, sino un derecho humano (un bien público); entonces, si se da pésima información (programas donde se ve violencia, discriminación, sexismo, etc., se miente, se desinforma, se ocultan las cosas, sólo se dice lo que le conviene a la empresa privada, etc.) se enferma a la sociedad. Por eso, se debe tener cuidado con la provisión de ese bien (la información) que se llama bien público. La estrategia de los emporios económicos siempre ha sido poseer un medio de comunicación, pero no para informar, sino para defender sus negocios (SECOM, jun. 2011). 3). Si una persona es banquera $\mathrm{y}$ tiene un canal de televisión en el que sus empleados son los periodistas y reporteros, en el momento en que un gobierno trata asuntos relacionados con los abusos de la banca, ¿pueden acaso esos periodistas o reporteros ser objetivos cubriendo ese asunto? (Fudamedios, set. 2007). 4) El caso del canal Teleamazonas: el dueño de ese canal también es dueño de la Plaza de toros de Quito; en una consulta popular se le preguntó al pueblo si querían que se evite que la muerte sea un espectáculo y que no se mate al toro en las corridas. En una situación como estas, ese canal jamás pudo tener una posición imparcial, "por eso no es bueno que se junte el poder informativo con el poder empresarial y el poder económico" (SECOM, mzo. 2012).

Cuando Correa asumió por primera vez la presidencia de Ecuador, el gobierno no tenía ningún canal de televisión: de siete canales nacionales, cinco eran de la banca, y cuando se quería eliminar gastos abusivos de la banca, el gobierno tenía que soportar una campaña mediática inmensa, donde se le acusaba a él de ser ladrón, corrupto, dictador, etc. De todo lo que la prensa dijo contra él nunca hubo ninguna consecuencia (SECOM, oct. 2015).

\section{Los grandes medios y las oligarquías}

Rafael Correa señala que en América Latina la prensa está en manos de las oligarquías; son emporios económicos que compran medios, pero no para dedicarse al periodismo, sino para defender sus emporios. A varios de los periodistas les ha preguntado: “¿Qué pobre tiene un medio de comunicación? ¿Qué pobre tiene un canal de televisión?" Explica que estos 
siempre han sido propiedad de las oligarquías. (SECOM, 05 may. 2014), y, "hablan de libertad, y entienden por libertad, proteger sus intereses y sus abusos" (SECOM, mzo. 2012).

Por el conocimiento que tiene de la región, en diálogo con Telemundo, sostiene que en el ámbito latinoamericano los grandes medios no son del pueblo, sino de un grupo pequeño; no son democráticos, porque no tienen controles ni contrapoder; son grandes monopolios mediáticos que controlan más del $80 \%$ de los medios de comunicación, y son familias generalmente vinculadas con la derecha y con los grupos de poder que siempre han dominado (Teleciudadanía, abr. 2016). En la mayoría de las entrevistas, cada vez que él hace esos cuestionamientos, los periodistas interpretan que está en contra de la libertad de expresión. En diálogo con Canal 11 de Costa Rica el reportero le consulta si "¿en Ecuador hay libertad de expresión?". La respuesta es irónica: "hay tanta falta de libertad de expresión que lo pueden publicar todos los días". Para él, la libertad de expresión sólo se logra en la medida en que la información deja de ser una mercancía (SECOM, ene. 2015).

Piensa que es necesario entender que la libertad de expresión no es el privilegio de los que tuvieron plata o heredaron una imprenta, sino un derecho de todos los seres humanos. No considera justo que mientras algunos no tienen la posibilidad de ejercer la libertad de expresión, otros, utilizando ese concepto, quieran con ello gobernar, juzgar y abusar (SECOM, mzo. 2012)

\section{La necesidad de nuevas leyes de comunicación}

Aunque todos los países tienen ley de medios, sin embargo, algunos periodistas le preguntan "¿por qué en Ecuador hay una ley de medios?" Hasta el 2013, la prensa se regía por la ley de 1970, de la época de la dictadura, que no contemplaba los medios impresos y con esa ley se podían clausurar emisoras radiales. En junio de 2011, en entrevista con el Canal 9 de Paraguay, pregunta: “¿en qué país del mundo no hay ley de medios, no hay regulación?” Un medio transmite información $y$, dependiendo de la información que dé, incide para bien o para mal en una sociedad, por eso se necesita una regulación, pero regular no es censurar (SECOM, jun. 2011).

El tema de la creación de una ley de medios en Ecuador había suscitado muchas opiniones y controversias. Dos meses antes de su aprobación, Correa tuvo una entrevista amplia en RTVE, donde atendió varias observaciones. Llama la atención que los periodistas se sorprendan y cuestionen que Ecuador fuera a tener una nueva ley, como si el resto de países no tuvieran leyes para eso. La entrevista es reveladora al respecto. La periodista le dice: "Su relación señor Correa con la prensa ecuatoriana es complicada y usted piensa que es necesario una nueva ley de prensa, ¿por qué?”. Él aprovecha la pregunta para mostrar cómo la prensa hace sesgos cuando trata los temas. En este caso, dice que su gobierno también tiene relaciones complicadas con algunos sindicatos, pero eso no es noticia para la prensa: "ahí ya se ve cómo la misma prensa se reconoce que es un poder fáctico", porque no es equitativa 
abordando los temas, sino que selecciona lo que le conviene. Pregunta: “¿En Europa no hay ley de prensa?" La periodista responde titubeando: "sí hay, pero no es igual a la ley de Ecuador" (aunque no sabe cómo es la ley de Ecuador). Las razones que usa Correa para justificar la regulación de los medios se mantienen en la misma perspectiva que ha estado defendiendo desde un principio: la función de los medios es informar. Dice: "se necesita una ley para que los medios se dediquen a realizar su función que es informar y no a defender intereses particulares". La información y la libertad son derechos de todos y no sólo del que tuvo dinero para comprarse un canal de televisión o comprar una imprenta; este es un poder muchas veces mayor que el poder del Estado. Defiende la idea de que cada país cree leyes que respondan a sus necesidades (Sucreranda, abr. 2013).

En los diálogos se percibe una apreciación reduccionista de algunos de los periodistas hacia la nueva Ley de Comunicación (además de que no la conocen); no es una ley "de medios", sino una "ley de comunicación”. Esta nueva ley no permite que una persona sea dueña de un banco y de un medio de comunicación a la vez; establece reglas claras para los medios y para los ciudadanos, y ambos pueden defender sus derechos; existe el derecho a la réplica y a la rectificación; busca la profesionalización del periodismo y la producción nacional en publicidad, música, arte y cultura.

Al igual que como se vio en el primer apartado, en donde se hace referencia a la dictadura de los medios, Correa en entrevista con CNN ahondó en el tema y señaló el poder inmenso que tienen los medios para moldear la opinión pública. En ese diálogo, la reacción que tuvo la periodista expresa la corta percepción que tienen quienes trabajan en los medios acerca de las dimensiones sociales de estos, o en todo caso, creen que el periodismo que ejercen es un periodismo neutral. La periodista pregunta: “¿Da por un hecho que podemos engañar a los ciudadanos?”. Y Correa explica: "Los políticos nos sometemos a controles en el escrutinio cada cuatro años, pero CNN ¿a quién se tiene que exponer?" Esta idea de Correa pone en entredicho la objetividad que la prensa cree tener y cuestiona su perennidad. La periodista dice que "para eso basta con que los ciudadanos cambien de canal." No percibe los reflejos condicionados creados por los medios; por eso Correa señala que esa afirmación es errónea, porque los ciudadanos toman decisiones con base en la información, y quien le da la información es el mismo medio sobre el que tienen que decidir (SECOM, 5 may. 2014). Dos semanas después, fue entrevistado por la televisión de Chile, donde habló de la falta de imparcialidad de los medios y expresó: "a CNN se le puede creer cuando hace un reportaje sobre un huracán, sobre un accidente, pero sobre cuestiones políticas el sesgo es evidente" (SECOM, 14 may. 2014).

\section{La independencia de un medio público}

Una sexta idea que desarrolla Correa en las entrevistas es acerca de la independencia de la prensa; propone la necesidad de diversificar la propiedad de los medios en propiedad comunitaria y propiedad pública, y buscar la propia democratización de los medios privados. Considera importante 
tener fuertes leyes de comunicación que permitan absolutamente la libertad de expresión, pero con responsabilidad, porque libertad sin responsabilidad ulterior es libertinaje, es abuso, es anarquía. Sostiene que las sociedades mediante su representación institucional que es el Estado, deben emitir leyes de comunicación que pongan claros estándares a esa comunicación y a esa libertad de expresión, tomando en cuenta los límites que establecen los tratados internacionales, así como la honra y reputación de las personas y la seguridad nacional. De lo contrario, se continuaría con los abusos de los grandes medios, los cuales seguirán dominando y gobernando, no por haber ganado una elección, sino por haber tenido dinero para comprarse una imprenta, y eso no es democrático (TV Pública Argentina, jun. 2012).

Cuando Correa hace referencia a la regulación de los medios, la tendencia de los periodistas es a pensar que lo que quiere es controlar la libertad de prensa y ejercer la censura previa. Desde el análisis que él hace, la censura previa práctica el control, actualmente, en la prensa burguesa y pone ejemplos de Ecuador, donde los dueños de los grandes medios habían separado a decenas de periodistas porque no aceptaron esas censuras; en otros casos, no les publicaron sus artículos y les presionaron para que atacaran el gobierno; o los amenazaban o perdían su trabajo si simpatizaban con el gobierno. Propone que haya un escrutinio público de controles cruzados, donde exista un consejo editorial y administrativo independiente de la administración pública del gobierno central (SECOM, mzo. 2012).
Desde que se aprobó la Ley de Comunicación, los grandes medios se encargaron de decir que en Ecuador ya no se podía criticar al presidente. La afirmación era falsa, no sólo porque la Ley no prohibía tal crítica, sino porque en la práctica diaria eso era lo que hacían los medios, y nunca tuvieron ninguna consecuencia. Pero no es lo mismo "crítica" que "injuria". Dice Correa: "Nadie puede estar en contra de que como presidente de la República o como hombre público estemos sujetos a más crítica, a más escrutinio”. Y pregunta: “¿Es crítica aseverar que soy un criminal de lesa humanidad, que he ordenado disparar sin previo aviso contra un hospital lleno de civiles? ¿Eso es opinión o monstruosa calumnia?" No es ni crítica, ni libertad de expresión. Dice: "Nadie está contra la crítica, así sea malsana, nadie está contra el escrutinio, pero no se pueden aceptar monstruosas mentiras e injurias; la lucha contra eso es la lucha por una verdadera libertad de expresión" (SECOM, mzo. 2012). Un año después de aprobada la nueva Ley de Comunicaciones en Ecuador, en entrevista con Charlie Rose de las cadenas estadounidenses CBS y PBS (transmitida para todo el mundo), éste le preguntó con sorpresa: “¿En Ecuador los medios de comunicación pueden criticarle?". Correa le dice: "por supuesto, y lo hacen todo el tiempo y todos los días" (SECOM, abr. 2014).

En las entrevistas analizadas, los periodistas siempre se refieren a las tensiones del ex mandatario con la prensa y la mayoría soslaya que el causante es Correa, e insinúan que se aprovecha del poder para confrontar a los medios. Sólo una de las entrevistas estudiadas muestra los ataques que la prensa realizó contra el presidente. Jorge Gestoso 
de Telesur, presentó unas frases que habían aparecido en la televisión ecuatoriana: "Le he dicho a Correa que es un resentido social y un frustrado sexual"; "se convirtió el presidente de la república en un sicario de la mentira"; "el presidente de la república es un mentiroso y un sinvergüenza"; "hipócrita, mediocre de Carondelet, farsante, cobarde, neonazi"; "aspirante a tirano"; "psicópata"; "pelea limpio hijo de perra" (OmarAli69, dic. 2012).

En reiteradas ocasiones, Correa ha dicho que su gobierno ha sido el más insultado de la historia, el más criticado y el más escrutado por la prensa; ellos podían calumniar, mentir, manipular, y nadie les podía contestar. "Ellos dicen corruptos, criminales, dictadores y eso es libertad de expresión. Uno les dice mentirosos, y eso es atentado a la libertad de expresión" (SECOM, ago. 2014). En entrevista con Will Grant de la BBC, éste le dice que ha habido "periodistas insultados en vivo por usted mismo", y Correa le replica:

¿Podría definir qué es insulto para usted? Porque que la prensa nos diga ladrones, dictadores, corruptos todos los días, resulta que no es insulto, pero si uno les dice mediocres, entonces es ofensa, es persecución a periodistas, es atentado a la libertad de expresión. ¿Acaso yo no tengo libertad de expresión?" (El Ciudadano, ago. 2012).

\section{Organizaciones internacionales y la libertad de prensa}

Existen algunas organizaciones no gubernamentales que, a semejanza de los grandes medios, despliegan su trabajo sin control, actúan deliberadamente y no admiten que se cuestione lo que hacen. Correa se refirió a dos de ellas en varias de las entrevistas.

La primera es la Sociedad Interamericana de Prensa (SIP), que en su opinión es una corporación de financieros de la comunicación, "exactamente igual que el gremio de los empresarios dedicados a la banca, o dedicados a los hoteles o dedicados a los casinos." Correa invita a que los periodistas no naturalicen la existencia y el quehacer de organizaciones como la SIP. Pregunta: “¿Quién les ha dado supremacía moral y los ha convertido en los árbitros?". Señala que "no tienen ninguna solvencia moral, sin embargo, se arrogan funciones de ser árbitros del bien y del mal, y en base a su poder mediático tratan de convencernos sobre eso" (OmarAli69, dic. 2012).

La segunda organización es Human Rights Watch que, al igual que la SIP, ha hecho observaciones contra los gobiernos progresistas de América Latina diciendo que no respetan la libertad de expresión. Correa cuestiona la razón de ser y la naturaleza misma de esa ONG. Haciendo uso de la ironía, pregunta a los periodistas: "¿Quién lo financia? ¿Quién lo puso de árbitro? ¿Ha sido fundado por la madre Teresa de Calcuta o por el Cártel de Sinaloa?" Sostiene que esas cosas deben ser de conocimiento del pueblo latinoamericano, para saber si son solventes para dar sus opiniones. Cuestiona a esas $\mathrm{ONG}$, porque se arrogan el derecho de hablar en nombre de la sociedad civil, asumiendo posiciones como si estuvieran por encima de los gobiernos elegidos democráticamente. Sus preguntas dejan a los entrevistadores sin respuestas: "¿A esas ONG quién los eligió? ¿Quién 
los escruta? ¿A quién presentan su rendición de cuentas? ¿Qué pueblo los aprueba o desaprueba cada cierto tiempo para tener legitimidad democrática?" Afirma que muchas de esas ONG son financiadas por los propios medios de comunicación, porque esa es la nueva alternativa de la derecha para impulsar políticas conservadoras desde fuera del Estado, pero no tienen ninguna representatividad: “¿Por qué nos tiene que preocupar lo que piense o deje de pensar una $\mathrm{ONG}$, respecto a gobiernos profundamente democráticos que tienen gran apoyo popular? (SECOM, mzo. 2012).

\section{Conclusiones}

Los análisis de las entrevistas realizadas a Rafael Correa revelan un pensamiento inédito sobre el tema de la libertad de prensa. Para él, los grandes medios de comunicación se han convertido en actores políticos y han abandonado su función primordial que es la de ofrecer información. Considera que son un poder desmedido en la democracia, que no tiene contrapoder, y configuran la sociedad desde los intereses privados que representan y hacia los fines que persiguen. Sostiene que los oligopolios de la comunicación han transformado la información en una mercancía.

Concibe la información como un derecho humano, por eso aboga para que ésta sea ofrecida de manera plural, independiente, democrática y objetiva, para que contribuya a la cultura, la educación, el conocimiento y el sano entretenimiento de la sociedad.

Por tratarse de un derecho humano (un bien común), la información debe ser provista por medios de comunicación públicos que sean controlados (administrados, supervisados) por la misma sociedad civil, no por el Estado, y para eso se deben crear leyes; esto contribuiría a tener una prensa más diversa, amplia y democrática. No aparece en el pensamiento de Rafael Correa ningún viso de censura ni límites a esas libertades; todo lo contrario, su propuesta es garantizar una libertad de prensa y una libertad de expresión para todos, no sólo para quienes tuvieron el privilegio de comprarse un canal de televisión o un periódico y usarlo con fines políticos, defendiendo sus emporios económicos y negándole a la sociedad la información como derecho humano.

\section{Referencias}

593Ecuador.(15 de enero de 2017). Entrevista a Rafael Correa 2017 Completa. [Video]. Recuperado de https://www.youtube.com/watch?v=d1W16ng1qAQ

Consuladosf. (23 de abril de 2012). Entrevista de Ismael Cala al Presidente Rafael Correa en CNN. [Video]. Recuperado de https://www.youtube.com/watch? $\mathrm{v}=\lg$ wu21aDAsY

El Ciudadano. (24 de agosto de 2012). Presidente Correa ofrece entrevista a BBC - Agosto 2012. [Video]. Recuperado de https://www.youtube. com/watch?v=514hpC6o5JM

Fundamedios. (8 de setiembre de 2007). Periodista argentino Jorge Lanata entrevista a Rafael Correa. [Video]. Recuperado de http://www.fundamedios .org/8-sep-2007-rafael-correa-entrevistado-en-fundamedios/ 
Lo que tu Buscabas. (28 de octubre de 2016). Ana Pastor habla de Rafael Correa en CNN, pero no de las críticas que recibió por entrevista YouTube. [Video]. Recuperado de https://www.youtube.com/ watch? $\mathrm{v}=\mathrm{zdRErFdn} 9 \mathrm{U} 4$

OmarAli69. (3 de diciembre de 2012). Dossier - Rafael Correa entrevistado por Walter Martínez. [Video]. Recuperado de https://www.youtube.com/watch?v=imQD80eRTPc

Peru info. (24 de mayo de 2012). Rafael Correa es entrevistado por Alvarez Rodrich. [Video]. Recuperado de https://www.youtube.com/ watch?v=QexcpAJ6tdE

Peru info. (17 de noviembre de 2013). Mario Saldaña: comentario final después de su encuentro con Rafael Correa. [Video]. Recuperado de https://www.youtube.com/ watch? $\mathrm{v}=\mathrm{muSHXrXMBx} 4$

SECOM. (29 de junio de 2011). Entrevista Presidente Rafael Correa con canal 9 de Paraguay. [Video]. Recuperado de https://www.youtube.com/ watch?v=ToeKrTvhoUI

SECOM. (10 de marzo de 2012). Entrevista al Presidente Rafael Correa con Jorge Gestoso. [Video]. Recuperado de https://www.youtube.com/ watch?v=GPelMDHx4yQ

SECOM. (21 de abril de 2014). El presidente Rafael Correa, entrevistado por Charlie Rose. [Video]. Recuperado de https://www.youtube.com/ watch?v=9vJuejPvgo4
SECOM. (5 de mayo de 2014). Presidente Rafael Correa ofreció entrevista a Ana Pastor de CNN. [Video]. Recuperado de https://www.youtube. com/watch?v=qzY8xgF3_t4

SECOM. (14 de mayo de 2014). Entrevista al Presidente Rafael Correa desde Chile. [Video]. Recuperado de https://www.youtube.com/ watch? $\mathrm{v}=\mathrm{nkbOPS} 94 \mathrm{Xls}$

SECOM. (8 de agosto de 2014). Entrevista del Presidente Rafael Correa en Canal Capital de Colombia. [Video]. Recuperado de https://www.youtube.com/watch?v=JpA4CxsadSk

SECOM. (29 de enero de 2015). Entrevista al Señor Presidente Rafael Correa con canal 11 Costa Rica. [Video]. Recuperado de https://www.youtube.com/watch? $\mathrm{v}=\mathrm{Bktl} \_1 \mathrm{rXcw}$

SECOM. (23 de octubre de 2015). Entrevista con el Presidente Rafael Correa con medio de comunicación AP en New York. [Video]. Recuperado de https://www.youtube.com/ watch? $\mathrm{v}=\mathrm{fcPhL}-\mathrm{yS} 3 \mathrm{sA}$

Quesada, M. (2008). "Una cita para entreverse": en torno a la entrevista. Recuperado de www.sagw.ch/ $\mathrm{dms} / \mathrm{sseh} /$ publications/untitled/ untitled11/08-Quesada

Sucreranda. (19 de marzo de 2012). Rafael Correa vapulea a Anita Pastor en Los Desayunos de TVE. HRW cartel de Sinaloa. Bancos. Cuba. [Video]. Recuperado de https://www.youtube.com/watch?v=zMQEvZ4itoo 
Sucreranda. (20 de abril de 2013). Rafael Correa vapulea a otra periodista de RTVE: Ana Ibáñez de La noche en 24 horas, clon Ana Pastor. [Video]. Recuperado de https://www.youtube.com/watch? $\mathrm{v}=\mathrm{Lr} 2 \mathrm{fLh} 6 \mathrm{f} 2 \mathrm{nU}$

Teleciudadanía. (12 de abril de 2016). Entrevista al Presidente Rafael Correa con Allan Villafaña de la cadena Telemundo, Nueva York. [Video]. Recuperado de https://www.youtube.com/watch?v=gJvV-R_YaUU
TV Pública Argentina. (30 de junio de 2012). V7Inter: Entrevista a Rafael Correa (1 de 2). [Video]. Recuperado de https://www.youtube.com/ watch? $=0 \mathrm{HAV} \times 1 \mathrm{nhYLo}$ 